\title{
JŨM MÃ AJAPRỲ? UMA ANÁLISE SEMÂNTICO- PRAGMÁTICA DOS NOMES PESSOAIS KRAHÔ
}

\section{JŨM MÃ AJAPRỲ? A SEMANTIC-PRAGMATIC ANALYSIS OF PERSONAL NAMES KRAHÔ}

\author{
Edivaldo Wakê Krahô* \\ Letícia Jôkàhkwỳj Krahô** \\ Maxwell Miranda***
}

\section{Introdução}

Jũm mã ajaprỳ? ${ }^{1}$ na língua krahô (mẽhĩ jarkwa), significa Qual é teu nome? e é uma pergunta frequentemente dirigida pelos krahô àqueles quando visitam suas aldeias, sejam esses mẽhĩ (indígena), de outras aldeias, ou cupẽ (não indígena). Aos cupẽ, é de costume, entre os krahô, oferecer-lhes o "nome" e, em seguida, marcar o "batizado" que se caracteriza como um rito especial de nominação em que são negociadas e trocadas algumas dádivas, como por exemplo, da parte do nominado, doar certa quantia de carne de algum animal de médio ou grande porte, como crôre (porco) ou prycàc (gado), enquanto da parte dos membros da comunidade, retribuir o nominado com presentes, como hõkre xà (colar), ipaxê xà (pulseira), càhà (cesto), pyty (esteira), entre outros.

0 povo Krahô, cuja autodenominação é mẽhĩ (carne de gente), é um dos povos Timbira (família linguística Jê Setentrional) que habita o cerrado brasileiro, na região norte do estado de Tocantins. Um dos traços mais marcantes da sociedade krahô, bem como de outras sociedades Jê, é a sua organização baseada na divisão e filiação dos indi-

\footnotetext{
* Professor Indígena da Educação Básica, tendo concluído o Curso de Magistério Indígena ofertado pela Secretaria Estadual de Educação e Cultura do Estado do Tocantins (SEDUC). Acadêmico do Curso de Licenciatura Intercultural, da Universidade Federal de Góias - UFG (Goiânia/GO/BR).

** Mestranda do Programa de Pós-Graduação em Antropologia Social pela Universidade Federal de Goiás - UFG (Goiânia/G0/BR). leticiakraho@hotmail.com.

**** Doutor em Linguística pela Universidade de Brasília (UnB) e Professor Adjunto I da Universidade Federal de Mato Grosso - UFMT (Barra do Garças/MT/BR). maxwellgm1@gmail.com.

1. 0 título deste trabalho foi inspirado no estudo de Ladeira (1982) sobre a troca de nomes e cônjuges entre os Ramkôkamekra, Apaniekra e Krahô.
} 
víduos em metades que se associam à vida político-administrativa, social e ritual. Com respeito aos ritos, os Krahô mantêm e realizam boa parte deles, considerando seu longo período de contato com a sociedade não indígena, desde o século XIX. Alguns desses ritos envolvem certo tempo de preparação e são realizados em épocas específicas ou fases da vida pessoal do indivíduo. Entre eles, o rito de transmissão de nomes é um dos mais característicos, o qual pode ocorrer de dois modos: (a) um nomeia os indivíduos que nascem no grupo, e (b) o outro nomeia os indivíduos estrangeiros que são incluídos no grupo (MELATTI, 1976, 1978). Nesse artigo, focalizaremos o segundo modo de transmissão do nome pessoal a partir da análise do rito, do ponto de vista linguístico ${ }^{2}$, caracterizando-o como um ato de fala específico, em uma perspectiva pragmática. Analisaremos a estrutura linguística e a semântica dos nomes pessoais, relacionando -os com o papel social que alguns indivíduos, sobretudo do sexo masculino, assumem em alguns ritos krahô de acordo com o nome do qual sejam portadores.

0 presente artigo está organizado nas seguintes seções. Na seção 1, apresentamos de modo sucinto o campo de estudo da onomástica; em seguida, na seção 2 , situamos a questão relacionada com a nominação em outras sociedades Jê. A seção 3 apresenta a organização social krahô e os modos pe- los quais os nomes pessoais são transmitidos. Na seção 4, mostramos como os nomes pessoais - tanto masculinos quanto femininos -, se distribuem em uma das metades wacmẽjê e catàmjê -, bem como a distribuição dos nomes masculinos no rito Kêtwajê, em 4.1. A associação entre nomes pessoais e certos papéis sociais desempenhados em alguns ritos é o foco da seção 5. Para exemplificar essa relação, destacamos o rito jàt jõpĩ (tora da batata). A seção 6 é dedicada à análise linguística dos nomes pessoais mais comuns e à sua semântica no âmbito da onomástica krahô, e outros processos especiais como aquele que forma nomes femininos mediante o acréscimo da palavra kwỳj. A seção 7, por sua vez, discorre sobre a Teoria dos Atos de Fala, com base em Austin (1990) e Levinson (2010), a partir da qual se fundamenta a análise linguística do discurso proferido no rito de nominação, na seção 8. As considerações finais destacam a importância da transmissão dos nomes pessoais na sociedade krahô e seus reflexos na estrutura e organização sociais como um todo.

\section{Onomástica: uma breve introdução}

0 ato de nomear é uma das características inerentes do homem. A nomeação de entidades reais e abstratas, desde a antiguidade clássica, especialmente na Grécia An-

2. Nota sobre a ortografia krahô. A maior parte dos grafemas consonantais (letras), indicados por $<>$, adotados na escrita da língua falada pelos Krahô correspondem aos grafemas do português, como segue: $<\mathrm{p}>$ : $/ \mathrm{p} /,<\mathrm{t}>: / \mathrm{t} /,<\mathrm{qu}>,<\mathrm{c}>: / \mathrm{k} /,<\mathrm{m}>: / \mathrm{m} /,<\mathrm{n}>: / \mathrm{n} /,<\mathrm{r}>: / \mathrm{r} / .0$ grafema $<\mathrm{h}>$ em início de sílaba corresponde a $<$ rr> do português; em final de sílaba, representa a consoante oclusiva glotal $/ 2 /$ que não possui equivalente em português, bem como o grafema $<\mathrm{g}>$ que representa a consonante nasal velar $/ \mathrm{y} /$ Os grafemas distintos do português são: $<\mathrm{k}>: / \mathrm{kh} /$, uma consoante velar oclusiva surda realizada com uma leve aspiração, $<\mathrm{x}>$ : /ts/, consoante africada alveolar surda, e os gliges (semivogais) $<\mathrm{j}>: / \mathrm{j} / \mathrm{e}<\mathrm{w}>:$ : $/$. Os grafemas vocálicos são: $<\mathrm{a}>: / \mathrm{a} /,<\dot{\mathrm{a}}>: / \mathrm{e} /,<\grave{\mathrm{y}}>: / \mathrm{\jmath} /,<\tilde{\mathrm{a}}>: / \tilde{\mathrm{a}} /,<\mathrm{e}>: / \varepsilon /,<\hat{\mathrm{e}}>: / \mathrm{e} /,<\tilde{\mathrm{e}}>: / \tilde{\mathrm{e}} /,<\mathrm{i}>: / \mathrm{i} /,<\tilde{\mathrm{l}}>: / \tilde{\mathbf{1}} /$, $<\mathrm{y}>: / \mathrm{i} /,<\tilde{\mathrm{y}}>: / \tilde{\mathbf{t}} /,<\mathrm{o}>: / \mathrm{o} /,<\hat{\mathrm{o}}>: / \mathrm{o} /,<\tilde{\mathrm{o}}>: / \tilde{\mathrm{o}} /,<\mathrm{u}>: / \mathrm{u} / \mathrm{e}<\tilde{\mathrm{u}}>$. 
tiga, foi tomada como um dos principais tópicos de reflexão filosófica, como por exemplo, em Crátilo, de Platão. A onomástica (do grego onoma $=$ nome) compreende o estudo dos nomes, e mantém íntima relação com outras ciências, como a Antropologia, Astronomia, Arqueologia, Folclore, História, Linguística, Sociologia, entre outras (ALGEO \& ALGEO, 2000). No caso da Antropologia, Algeo e Algeo (2000) destacam a contribuição da onomástica, considerando que os "padrões de nomeação para pessoas variam consideravelmente de uma cultura a outra” (p. 265), e que a nominação do indivíduo reflete certos padrões de organização e práticas sociais, sistemas de parentesco, e ainda implica algumas restrições, por exemplo, evitar que o indivíduo fale seu próprio nome, como entre os Kĩsêdjê (Suyá) (Tempty Suyá, comunicação pessoal).

No âmbito da onomástica, comumente, destaca-se o estudo dos nomes próprios, a partir dos quais é comum subdividir em dois tipos principais: nomes de lugar ou toponimia e nomes pessoais ou antroponímia. Com respeito aos nomes pessoais, Bright (2003) discute a universalidade dos nomes pessoais. Entre os antropólogos, segundo o autor, há um certo folclore em considerar que os nomes pessoais existem em todas as sociedades. Essa concepção advém do fato de que pessoas em pequenas comunidades isoladas não têm nomes pessoais, isto é, os indivíduos não são referidos por nomes específicos para elas, mas por meio de expressões descritivas. Bright (2003), então, levanta as seguintes questões: tal sociedade existe? Tal sociedade é possível? Para o autor, deve-se "perceber que muitas pessoas no mundo não têm tais sistemas altamente organizados de nomeação pessoal como estamos acostumados em nossas próprias sociedades” (BRIGHT, 2003, p. 672). Partindo dessa premissa, ainda segundo o autor, tais sociedades que fariam uso de expressões descritivas para nomear seus membros não existem e sugere que "que o uso de nomes pessoais, tendo vários níveis de descrição, é um universal sociolinguístico da espécie humana"3 (p. 673).

Contudo, expressões descritivas para nomeação de pessoas parecem ser comuns entre os Canela-Ramkôkamekra, um dos povos Timbira no estado do Maranhão. Crocker (2009), ao mencionar sobre a criação de nomes pessoais nessa sociedade, relata o caso de uma mulher que, com raiva de seu marido, retirou metade das varas da cama de jirau, impedindo-o que se deitasse junto a ela. Ao lembrar da raiva pelo seu marido, posteriormente, deu à filha de seu irmão o nome pàl-rë (cama-jirau-jogada-para-baixo). Fatos como esse não foram observados na amostra de nomes pessoais coletados junto aos Krahô e nem na criação espontânea de novos nomes a serem transmitidos, o que indica tratar-se de uma distinção entre os dois povos quanto às estratégias para nomeação de seus indivíduos.

\section{Nominação em sociedades Jê: uma vi- são geral}

Alguns autores têm destacado o papel que a nominação desempenha nas sociedades Jê: Lea (1986, 2012), entre os Mẽbengokre Mẽtyktire; Lopes da Silva (1986), entre os Xavante; e Juracilda Veiga (2006) en-

3. Texto original: [...] that the use of personal names, having varying levels of descriptiveness, is a sociolinguistic universal of the human species [...] (BRIGHT 2003, p. 673). 
tre os Kaingang. Mesmo em se tratando de sociedades que compartilham certos traços culturais e linguísticos, o sistema de nominação difere consideravelmente de uma para outra, nas suas regras de transmissão e nas funções que assume em cada sociedade.

Entre os Kaingang do Sul, a nominação do indivíduo está relacionada à filiação do pai, conforme a sua metade da qual seja pertencente - Kanhru, Wonhétky, Kame) e Votor. De acordo com Veiga (2006, p. 145), “o nome Kaingang (jiji) é uma entidade social e cerimonial: com o jiji o indivíduo recebe os papeis sociais e/ou cerimoniais correspondentes ao nome". Entre as funções cerimoniais correspondentes ao nome pessoal do indivíduo, Veiga (2006) cita a categoria péin, que está presente em ambas as metades kanhru e kamẽ. As pessoas portadoras de nomes associados a essa categoria são encarregadas pelos serviços fúnebres, os quais lhes oferecem perigos, segundo a crença de que mesmo após a morte o espírito do indivíduo ainda vagueia pela aldeia dos vivos e deseja levar seus parentes consigo. Outra função cerimonial é a "abertura do buraco" atribuída à seção Votor, ou seja, "a passagem por onde os espíritos dos ancestrais (ngufõ) e os espíritos dos mortos (véinkuprĩng) vêm participar do $K i$ kikoi" (VEIGA,2006, p. 150).

Outro traço comum à maioria das sociedades Jê reside no fato de que um indivíduo pode ter vários nomes, os quais são adquiridos ao longo de sua vida. Entre os Xavante, de acordo com Silva (1986), há homens que chegam a ter de seis a oito nomes. Contudo, ao contrário de outros povos Jê, no caso Xavante, a atribuição de diferentes nomes em distintas fases da vida está liga- da às categorias de idade masculinas. Desse modo, "os nomes masculinos Xavante acompanham as passagens cruciais de um homem no processo de maturação biológica e social: são marcas de fases determinadas da vida de um indivíduo" (SILVA, 1986, p. 63-65).

\section{Estrutura social e a transmissão dos no- mes pessoais entre os Krahô}

A divisão das sociedades Jê, de um modo geral, em pares de metades é uma das características mais marcantes desses povos que habitam estas terras: desde a região amazônica - no norte de Mato Grosso, sul e sudeste do Pará; os campos de cerrado - no norte e centro do Tocantins e sul do Maranhão -; até o planalto, nos estados de São Paulo, Paraná, Santa Catarina e Rio Grande do Sul.

A nominação dos indivíduos nas culturas Jê é bastante peculiar e é orientada conforme alguns princípios sociais que regulam, em grande parte, seu sistema de parentesco. Nimuendajú (1946, p. 77) menciona sobre a filiação de indivíduos Canela-Ramkokamekrá, tanto do sexo masculino quanto feminino, a uma das metades, ka'makra e $a t y$ 'kmakra, e destaca que cada pessoa pode adquirir de dois a oito nomes. 0 autor ainda observa que somente os indivíduos do sexo masculino pertencem a um dos seis grupos da praça. 0 trabalho de Nimuendajú (1946) fornece-nos também informações sobre as regras de transmissão dos nomes pessoais, entre os Canela-Ramkôkamekra, que "são transferidos aos meninos através da linha matrilinear, às meninas através da linha patrilinear" (p. 78)

4. Texto original: “[names] are transferred to boys through the matrilineal line, to girls through the patrilineal line” (NIMUENDAJÚ, 1946, p. 78) 
A sociedade krahô divide-se em duas metades principais: catàmjê e wacmẽjê. Essas metades associam-se a uma série de elementos simbólicos que opõem entre si, sendo, portanto, um traço típico das sociedades dualistas (LÉVI-STRAUSS,1982). A primeira metade associa-se ao período chuvoso (tahti), à noite (awcapàt), à lua (pytwrỳ), à periferia da aldeia ( $k r i \tilde{~ c a p e), ~ e n q u a n t o ~ a ~ s e-~}$ gunda metade relaciona-se ao período seco (incrà), ao dia (amcro), ao Sol (pyt) e ao pátio da aldeia ( $k \dot{a})$ (MELATTI, 1978). A essas metades, semelhante à sociedade Canela-Ramkôkamekra, filia-se uma série de nomes pessoais (MELATTI, 1973, 1976, 1978) ${ }^{5}$.

Indivíduos de ambos os sexos são distribuídos em uma das metades, wacmẽjê ou catàmjê, de acordo com o seu nome pessoal. Entre os Krahô, para os indivíduos nascidos no grupo, os nomes pessoais são transmitidos pelos parentes consanguíneos. Aos do sexo masculino, transmite-se o nome do irmão da mãe, pai da mãe, o pai do pai e seus primos paralelos, o qual é tratado pelo nome quêtti pelo indivíduo que recebeu seu nome, e esse é tratado pelo nome ipantu pelo seu nominador. Já os indivíduos do sexo feminino é transmitido o nome da irmã do pai, mãe do pai, filha da irmã do pai, mãe da mãe e suas primas paralelas. Referem-se à sua nominadora pelo nome $t y j$, a qual se refere à pessoa a quem lhe transmitiu seu nome pelo termo ipantu (MELATTI, 1976, p. 4). Já a transmissão de nomes pessoais a não-indígenas - geralmente são pessoas com as quais os Krahô se relacionam diária ou eventualmente, e têm relações amis- tosas -, ocorre quando qualquer indivíduo quer repassar seu nome a outra pessoa e essa o aceita, sem que haja qualquer vínculo consanguíneo. Como o foco do presente artigo é o segundo modo de transmissão de nome pessoal, é provável que o discurso proferido difira em conteúdo e estrutura daquele para os membros nascidos no grupo. Por não dispormos de dados que confırmem essa hipótese, analisaremos, do ponto de vista linguístico, o discurso usado no rito de nominação.

Além dessa divisão principal, cujos reflexos incidem sobre o nome do indivíduo, há outros ritos que se organizam de acordo com o nome pessoal, como o kêtwajê (caris novos) e jàt jõpĩ (tora da batata). No rito do kêtwajê, somente os indivíduos do sexo masculino são agrupados em um dos oito grupos que constituem as metades kàj rum pê càxà (partido do lado de cima), ficando a leste, e harã rum pê càxà (partido do lado de baixo), a oeste da praça, com quatro grupos em cada metade. A Figura 1, na seção 4, ilustra a distribuição dos grupos das metades kàj rum pê càxà e harã rum pê càxà (MELATTI, 1976).

Melatti (1976), em seu artigo, Nominadores e genitores: um aspecto do dualismo $c r a \hat{o}^{6}$, oferece-nos descrição e análise sistemáticas dos princípios socioculturais que norteiam o sistema de transmissão dos nomes pessoais do povo Krahô. Nesse trabalho, o autor distingue dois conjuntos de parentesco consanguíneos: nominadores e genitores. A distinção entre esses dois conjuntos, em princípio, não pressupõe uma rela-

5. A recorrência de nomes pessoais pode variar de uma aldeia para outra. Nesse estudo, apresentamos os nomes mais recorrentes na aldeia Cachoeira.

6. Embora Melatti (1976) forneça importantes informações sobre o sistema de nominação krahô, bem como suas regras de transmissão, não apresenta o conjunto de nomes pessoais que são categorizados em cada uma das metades e submetades cerimoniais. 
ção de oposição, mas de complementaridade. Aos genitores compete a geração e formação biológica do indivíduo, enquanto aos nominadores é-lhes reservada a formação social do indivíduo através da transmissão do seu nome, transferindo-lhe certas funções e prerrogativas no âmbito da vida sociocultural e da relação com outras pessoas.

Melatti $(1973,1976)$ ainda destaca a figura de personagem que é encarnada, com respeito aos papeis sociais que os indivíduos assumem quando lhes são transmitidos o(s) nome(s) pelo seu/sua respectivo(a) nominador(a) quêtti (para os homens) e tyj (para as mulheres). Nesse sentido, cada nome pessoal Krahô "corresponderia a um personagem, isto é, um ser que, embora encarnado em ocasiões diversas por diferentes atores, repete sempre as mesmas ações e mantém sempre as mesmas relações com os seres da mesma espécie" (MELATTI, 1973, p. 19). Esse fato torna-se evidente no rito jàt jõpin (tora da batata), o qual é realizado geralmente no mês de abril, em que certos personagens envolvidos na execução das etapas do rito são identificados conforme o seu nome pessoal, como é o caso do personagem hôxwa (uma espécie de palhaço), que tem por função animar a comunidade por meio de gestos jocosos, provocando-lhes o riso.

Apresentamos, na próxima seção, a distribuição dos nomes pessoais masculinos e femininos a partir da divisão wacmẽjê e catàmjê e, em seguida, a distribuição de alguns nomes pessoais masculinos nos grupos que compõem as metades kàj rum pe càxà e harã rum pe càxà, no rito do ketwajê. Mostramos ainda, em \$3.1, a correlação entre os nomes pessoais e os personagens do rito jàt jõpĩ (tora da batata).

\section{Distribuição dos nomes pessoais krahô}

No Quadro 1, apresentamos os nomes pessoais masculinos associados a uma das metades wacmẽjê e catàmjê. Em seguida, no Quadro 2, mostramos a distribuição dos nomes femininos.0s nomes pessoais foram registrados conforme são usados nos documentos pelos Krahô. Desse modo, optou-se por seguir a padrão ortográfico da língua e não separar as palavras nos casos em que o nome é composto por mais de uma palavra, como será visto na seção 4 , com respeito à estrutura linguística dos nomes pessoais. 


\section{Hũmre japrỳ (Nomes masculinos)}

Wacmẽjê japrỳ (Nomes Wacmẽjê)

Hapôr

Xêpỳm

Pànhi

Iromtep

Rophi

Rontehhô

Wakê

Kràc

Krỳjtep

Kẽncaprêc

Hũhkop

Teptyc

Cupẽhtyc

Tepjêt

Piikẽn

Ihprỳ

Kàj

Krãkãmkruw

Caprỳ

Xore

Hĩxwatyc

Põhypej

Rõhkrã

Põhy=krat

Pôtyt

Capran

Kẽnkrat

Roptyc

Tuhtê

Côhtetet

Wewe cabelo de milho

morcego caído

osso da arara

mato vermelho

osso do cachorro

pelo da perna de tucum

chico preto (ave)

pau de terra (árvore)

papagaio vermelho

pedra laranjada

unha dele

peixe morto

não índio negro

peixe pendurado

dançar (junto)

palha (de milho)

machado

flecha na cabeça dele

vazio

raposa

casco preto da pata

milho bom

cabeça de tucano

pé de milho oco

palha amarrada

jabuti

pedra oca

cachorro morto

ferida da barriga

água limpa

borboleta
Catàmjê japrỳ (Nomes Catàmjê)

Xôtyc

Crate

Pêhà

Tehhi

Xàj

Kõc

Pàrhy

Cuhêhkê

Rõrehhô

Krôkrôc

Cacro

Hôhkràkràc

Hapykrit

Pàt

Yahhe

Xêpjaka

Hũhtê

Jõhi

Prehtyc

Pêphà

Cuxỳ

Ahpràcuxwa

Crerô

Pohi

Côrã

Hõrkãkã

Cupacà

Ajtà

Cacôxen

Ihkôhkrãn

Hajêhi fruto preto

perna da paca

xexeu (pássaro)

osso da canela da perna

pica-pau

camaleão

pimenta

arco raspado

palha de coco babaçu

espécie de pássaro

quente

barulho da folha

rabo arrepiado

tamanduá

perna aberta

morcego branco

mão dele ferida

cóccix

cinto preto

formigão

cheiroso

chama (de fogo) gostosa

inhame

osso do veado

flor da água

fibra do olho de buriti

casca de mandioca-cipó

maribondo de carne

líquido doce

palha de palmito curta

osso de algum animal 
Cahãj japrỳ (Nomes femininos)

\begin{tabular}{llll} 
Wacmẽjê japrỳ (Nomes Wacmejê) & \multicolumn{2}{l}{ Catàmjê japrỳ (Nomes Catàmjê) } \\
Craxỳ & paca ardilosa & Pytô & urucum \\
Jõxen & pessoa bondosa & Krãry & cabeça comprida \\
Pryrê & desvio de caminho & Caràhtu & barriga do veado catingueiro \\
Mãkrỳt & bico da ema & Wet & calango \\
Cahhuc & socar & Côcahàc & água falsa \\
Jõkà & pele da bunda & Incà & sobra (de algo) \\
Cagãcakê & tirar cobra & Kucatep & rosto vermelho \\
Kẽnpej & pedra bonita & Jàt & batata-doce \\
Ihkror & pintar em forma de círculo & Kwỳrhô & folha de mandioca \\
Wakỳ & facão & Põcuhtô & cuspir para fora \\
Irãhcaprêc & flor laranja (de alguma planta) & Cahtẽc & soprar (para encher) \\
Pyhkĩn & gostar de urucum & Hypỳm & semente caída \\
Pjêhkỳ & terra fedida & Pytẽc & mutum
\end{tabular}

Fonte: autoria própria.

\subsection{Distribuição dos nomes pessoais no ri- to kêtwajê}

Como foi mencionado, na seção 3, somente os nomes masculinos associam-se a um dos quatro grupos que constituem cada uma das metades harã rum pê càxà (partido do lado de baixo) e cỳj rum pê càxà (partido no lado de cima). Na Figura 1, mostramos a distribuição e a disposição espacial dos oito grupos no rito do kêtwajê. Em seguida, nos Quadros 3 e 4, apresentamos os principais nomes pessoais pertencentes a um dos quatro grupos que constituem cada metade. 


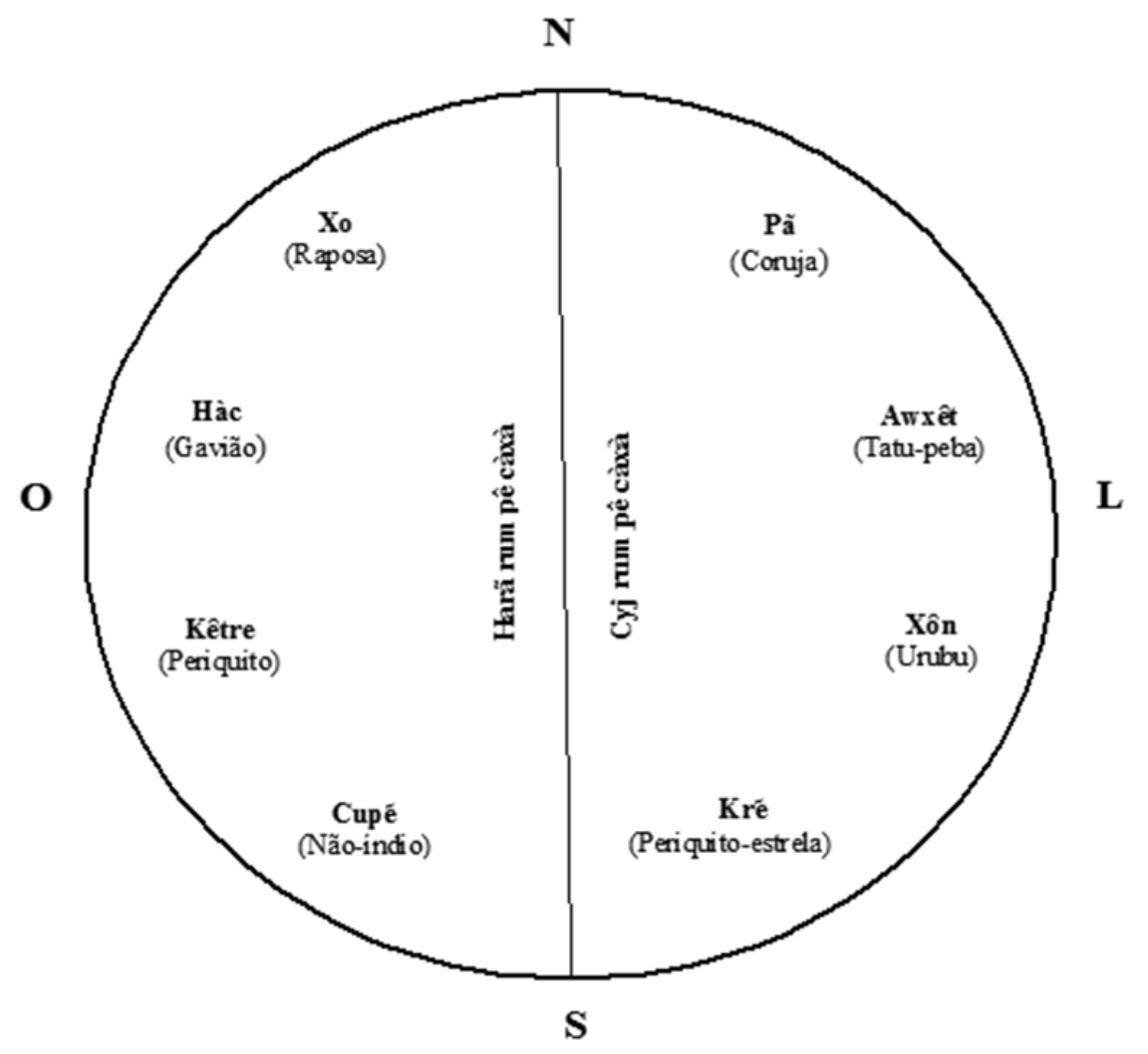

Fonte: MELATTI, 1978.

Quadro 3 - Distribuição dos nomes pessoais no rito kêtwajê

Harã rum pê càxà (partido do lado de baixo)

Xo (Raposa)

Krôkrôc - espécie de pássaro

Wakê - chico preto

Krãhkãmkruw - flecha na cabeça

Hajêhi - osso de animal

Papôr - espécie de planta, etc.

Hàc (Gavião) Kêtre (Periquito)

Hàctocot - filhote de gavião Cahxêt - espetar Tuhtê - ferida da barriga

Ropkur - onça comida

Kàkà - espécie de pássaro, etc.
Piikẽn-dançar junto

Pôtyt - periquito
Cupe (Não índio)

Pôjtehhô - folha de jatobá

Krahxêt - paca assada

Ajehi - tipo de andorinha

Fonte: autoria própria. 
Cỳj rum pê càxà (Partido no lado de cima)

$\begin{array}{lll}\text { Pã (Coruja) } & \text { Awxêt (Tatu peba) } & \text { Xôn (Urubu) } \\ \text { Hahàkre - final do } & \text { Kwỳhcakê - arrancar } & \text { Xêpỳm - morcego caído } \\ \text { buraco do pau } & \text { um bocado } & \text { Tehhi - osso da perna } \\ \text { Kẽncaprêc - pedra } & \begin{array}{l}\text { Xwarêt - espécie } \\ \text { de formiga }\end{array} & \text { Jõhi - cóccix } \\ \text { laranjada } & & \end{array}$

Krẽ (Periquito-estrela)
Cakrô - espécie de
vestimenta
Põhykrat - pé de milho
oco

Hawỳ - broto de pati

(espécie de palmeira)

Fonte: autoria própria.

\section{Nomes pessoais e papeis sociais na so- ciedade krahô}

$\mathrm{Na}$ transmissão de nomes pessoais, o(a) nominador(a) quetti/tyj transfere também ao seu nominado ipantu certos papeis sociais e cerimoniais que estão vinculados a certos nomes do qual seja seu portador. Esse é o caso, por exemplo, do rito jàt jõpĩ (tora da batata-doce), o qual é realizado no mês de abril. A finalidade desse rito, antigamente, envolvia a combinação ou a realização de casamentos pelas famílias, que trocavam kwỳr cupu (paparutos) ${ }^{7}$ entre si. Como será visto nessa seção, algumas funções são desempenhadas nesse rito conforme o nome pessoal. Não nos foi possível fazer um levantamento exaustivo de todos os nomes pessoais associados aos personagens que têm algum tipo de participação durante a realização do rito. Desse modo, destacaremos somente aqueles principais.
0 rito jàt jõpĩ inicia com o corte da tora de madeira, e não de buriti crow, no dia anterior em que será carregada na corrida entre as metades wacmejjê e catàmjê que ocorrerá no dia seguinte. Só podem cortar a tora aqueles que possuem o mesmo nome pessoal de hôxwa, como veremos adiante. Antes de começar a corrida com as toras, duas crianças são escolhidas aleatoriamente, cada uma associada a uma metade, as quais não têm nomes específicos, e é-lhes dado um soco em cada uma das coxas delas e, em seguida, disputam uma pequena corrida em direção a uma árvore para roer a casca do tronco.

Após a realização da corrida, um indivíduo corre pelo krĩ cape, rua em torno da qual as casas estão dispostas, acompanhado por uma de suas parentes, que lhe derrama água sobre o corpo. Esses indivíduos possuem os seguintes nomes pessoais: $P y$ cajcô (cachamorra), Pànhàc (arara-gavião),

7. kwỳr cupu (paparuto) é uma comida típica krahô preparada com massa de macaxeira e acrescentados pedaços de carne, os quais são envolvidos em palhas de bananeira. É colocada para assar sobre o moquém kyj e, em seguida, joga-se terra, a fim de que cozinhe por um certo tempo. Geralmente, o kwỳr cupu é preparado no final do dia anterior e retirado do moquém no dia seguinte pela manhã e compartilhado entre os familiares. 
Põhyhkrat (pé de milho oco), Krôkrôc (espécie de pássaro). A mulher que acompanha esse indivíduo, por sua vez, tem o nome $\mathrm{Po}$ tekre (buraco da perna do veado).

Ao longo da realização do rito, ao final da tarde, inicia-se a etapa em que as batatas são arremessadas, percorrendo o krĩ cape. Essa etapa é acompanhada pela execução de diversas músicas específicas desse rito. $\mathrm{Na}$ ocasião, formam-se dois grupos de pessoas: um que atira as batatas e outro que as recolhe. 0 primeiro grupo é constituído por pessoas que possuem nomes específicos, enquanto no segundo grupo não há especificação quanto ao nome. Entre os membros que constituem o primeiro grupo distinguem-se os seguintes personagens e seu respectivo nome pessoal: jàt hõrcatê - doador da batata; Hajêhi - osso de algum animal; jàt rẽn catê - arremessador da batata; Pykaj - esperar urucum. Esse grupo é seguido pelo increr (cantor) que tem o nome Kẽnkrat (pedra oca) e pela hõkrepôj (cantora), cujo nome pessoal é Hypỳm (semente caída).

Um dos personagens principais do rito jàt jõpĩ (tora da batata-doce) é o hôxwa (palhaço). Seu aparecimento marca o encerramento da festa à noite no pátio aldeia. 0 hôxwa tem como função animar as pessoas por meio de mímicas, provocando-lhes o riso. Os nomes pessoais, que são identificados como hôxwa, são: Crate (perna da paca), Cupõ (esfregar [algo]), Ahprac (dois), $\mathrm{Ha}$ pôr (cabelo de milho), Krôkrôc (espécie de pássaro), Jõhi (cóccix), Teptyc (peixe morto), Pàrhy (pimenta), Ahpràcuxwa (chama [de fogo] gostosa). No momento em que as batatas são arremessadas pelo jàtrẽn catê (jogador da batata), os indivíduos que possuem o nome de hôxwa não podem estar entre aqueles que as recolhem.

A seguir, na seção 6, destacamos as bases lexicais que servem como fontes para

os nomes pessoais, e analisamos a estrutura linguística e a semântica desses nomes em krahô, com a finalidade de compreender os mecanismos linguísticos, sobretudo as classes lexicais (nome, adjetivo, posposição, verbo) envolvidas no processo de composição de antropônimos, tendo em vista que em alguns casos é empregada mais de uma palavra na formação desses nomes.

\section{Estrutura linguística e a semântica dos nomes pessoais krahô}

Do ponto de vista linguístico, a constituição dos nomes pessoais krahô tem como base lexical, na maior parte das ocorrências, elementos que se referem ao universo natural, tal como a fauna e flora, bem como itens lexicais que designam partes do corpo ou partes de um todo, tanto de plantas quanto de animais, qualidades e eventos, que se associam prototipicamente às classes de palavras nome, adjetivo e verbo.

Com respeito ao número de palavras envolvidas na composição dos nomes e ao significado que remetem: em (1) apresentamos as que são constituídas somente de um elemento que designam amimais e, em (2), as plantas.

$\begin{array}{ll}\text { 1) ANIMAIS } & \\ \text { Wet } & \text { calango } \\ \text { Wewe } & \text { borboleta } \\ \text { Kõc } & \text { camaleão } \\ \text { Pàt } & \text { tamanduá } \\ \text { Pytẽc } & \text { mutum } \\ \text { 2) } & \\ \text { PLANTAS } & \\ \text { Pytô } & \text { urucum } \\ \text { Jàt } & \text { batata-doce } \\ \text { Crerô } & \text { inhame }\end{array}$


Além desses, há nomes que se referem atualmente a utensílios da cultura material, como Wakỳ (facão) e Kàj (machado). Como se pode observar, não são comuns nomes pessoais dessa natureza no repertório krahô, e é provável que tais nomes tenham sofrido mudança semântica em relação aos referentes que originalmente designavam, já que se tratam de objetos que foram introduzidos pelo contato com a sociedade não

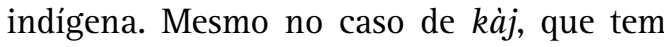
a forma derivada kàjre, palavra usada para designar a machadinha de pedra semilunar, que é uma das principais personagens do mito de Hartãt, o significado de machado a ela atribuído pode não corresponder historicamente à sua função na sociedade krahô antes do contato com não indígenas e que tal mudança semântica tenha sido motivada por analogia aos usos que dela são feitos entre os sertanejos da região com os quais os krahô passaram a ter contatos frequentes desde o século XIX.

Os nomes pessoais que são constituídos por mais de um elemento ${ }^{8}$ têm seu elemento central (núcleo) antecedido por um determinante nominal ou seguido por um modificador (adjetivo). A gramática krahô distingue esses dois domínios sintáticos, em que na relação de determinação o segundo elemento é determinado pelo primeiro (DET + NúClEo), ao passo que na relação de modifıcação, o primeiro elemento é modificado pelo modificador, que o segue imediatamente (NÚCLEO + MODIF). A relação semântica estabelecida no primeiro caso envolve partes do corpo ou partes de um todo, como em (3), enquanto no segundo caso a relação de modificação implica na atribuição de uma qualidade ao nome (núcleo) a que se refere, como nos exemplos em (4).

3) PARTES DO CORPO OU DE UM TODO (PLANTAS E ANIMAIS)

$\begin{array}{ll}\text { Pàn=hi } & \text { osso da arara } \\ \text { Kra=te } & \text { perna na paca } \\ \text { Mã=krỳt } & \text { bico da ema } \\ \text { Caràh=tu } & \begin{array}{l}\text { barriga do veado } \\ \text { catingueiro }\end{array} \\ \text { Kwỳr=hô } & \text { folha de mandioca } \\ \text { Cupa=cà } & \text { casca de mandioca- } \\ & \text { cipó }\end{array}$

(4) ATRIBUIÇÃO DE QUALIDADE

$\begin{array}{ll}\text { Cô=cahàc } & \text { água falsa } \\ \text { Cô=tehtet } & \text { água limpa } \\ \text { Jõ=xen } & \text { pessoa bondosa } \\ \text { Krã =ry } & \text { cabeça comprida } \\ \text { Kàh=pytĩ } & \text { casca pesada } \\ \text { Kẽn=krat } & \text { pedra oca } \\ \text { Põhy=pej } & \text { milho bom } \\ \text { Krỳj=tep } & \text { papagaio vermelho } \\ \text { Kẽn=caprêc } & \text { pedra laranjada } \\ \text { Xô=tyc } & \text { fruto preto } \\ \text { Xêp=jaka } & \text { morcego branco }\end{array}$

Observamos casos excepcionais de nomes pessoais que são formados de um elemento designando qualidade, como Cuxỳ (cheiroso), Cacro (quente) e Caprỳ (vazio). Esses itens lexicais, como seria esperado, não ocorreriam isolados, mas em uma relação de modificação, como aqueles apresentados em (4).

Consideramos ainda neste grupo, os nomes pessoais que são formados a partir da

8. Aqui usamos o símbolo = para indicar a fronteira entre as palavras, ainda que na escrita ortográfica usada pelos krahô tais composições não sejam separadas. 
combinação de um NOME + NOME DE AÇÃo (MIRANDA, 2010, 2014). A nominalização de temas verbais é uma das peculiaridades mais evidentes da gramática krahô, bem como na maior parte das línguas Jê. Tomemos como exemplo o nome de ação $t y$ - $k$ (morto) em (5), o qual é derivado a partir do acréscimo do sufixo $-k$ ao tema verbal ty (morrer) ${ }^{9}$. Nomes de ação referem-se a eventos e/ ou processos relacionados com a base verbal a partir da qual derivaram e equivalem, nesse contexto, ao particípio em português, adquirindo funções típicas de adjetivo, como nos exemplos (5).

(5) NOME + NOME DE AÇÃO

$\begin{array}{ll}\text { Xêe }=\text { ỳm } & \text { morcego caído } \\ \text { Pjêh=kyे } & \text { terra fedida } \\ \text { Tep=jêt } & \text { peixe pendurado } \\ \text { Rop=tyc } & \text { cachorro morto } \\ \text { Hapy=krit } & \text { rabo arrepiado } \\ \text { Cuhê(h)=kêe } & \text { arco raspado } \\ \text { Pô=tyt } & \text { palha amarrada } \\ \text { Rop=kur } & \text { onça comida }\end{array}$

Há nomes pessoais que são formados somente por verbos, como Cahhuc (socar), Cahxêt (espetar), Cahtẽc (soprar [para encher]) e Piikẽn (dançar [junto]). Outros nomes, por sua vez, são constituídos pelo verbo e seu complemento (objeto direto), conforme a ordem canônica dos constituintes (S)OV em krahô, isto é, (SUJEITo) OBJETO DI-
RETO + VERBO. Exemplos desse tipo são $\mathrm{Ca}$ gã cakê (cobra tirar [tirar cobra]), Kwỳh cakê (bocado arrancar [arrancar um bocado]), $P y$ kin (urucum gostar [gostar de urucum]).

Verificamos a partir da amostra coletada que os nomes pessoais são formados a partir das classes de palavras principais da língua, isto é, nomes, adjetivos e verbos. Contudo, o uso de posposições parece não ser tão comum na constituição de nomes pessoais em krahô. 0 único caso foi Krã kãm kruw (cabeça em flecha [flecha na cabeça]), em que ocorre a posposição locativa kãm (em).

\subsection{Nomes pessoais femininos com kwỳj}

Destacamos nesta seção uma peculiaridade quanto à formação dos nomes pessoais krahô, a qual envolve o uso do elemento morfológico kwỳj, exclusivo somente para nomes pessoais femininos. Esse elemento é bastante produtivo na formação de nomes pessoais e é exclusivo para essa finalidade. Logo, não deve ser confundido com a expressão da categoria gramatical de gênero, visto que em krahô gênero não é marcado formalmente, mas expresso por meio de outros dispositivos gramaticais. Os nomes pessoais femininos formados pelo elemento $k w y j j$ abrangem, sobretudo, itens lexicais referentes a fauna e flora. Esses nomes opõem entre si quanto à filiação às metades $W a$ cmẽjê e Catàmjê, como mostra o Quadro 5.

9. 0 sufıxo nominalizador de nome de ação tem as seguintes formas: $-r,-t,-n,-m$ e $-k$ (cf. Miranda 2010, 2014). Todavia, nem todos os temas verbais ocorrem com uma dessas formas do sufixo nominalizador e não recebem expressão fonológica, sendo marcado por um morfema zero - $\emptyset$. 


\begin{tabular}{|c|c|}
\hline Wact & \\
\hline 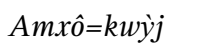 & rato $=$ FEM \\
\hline Prum $=k w \grave{y} j$ & formiga vermelha $=$ FEM \\
\hline Tereh $=k w \grave{y j}$ & pé de jatobá=FEM \\
\hline Cũmtũm=kwỳj & capivara=FEM \\
\hline$C a h y=k w \grave{j}$ & amendoin=FEM \\
\hline 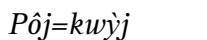 & fruto do jatobá $=$ FEM \\
\hline
\end{tabular}

Fonte: autoria própria.

Ao analisar a estrutura linguística dos nomes pessoais podemos identificar algumas regularidades com relação aos itens lexicais (nomes, verbos, adjetivos) envolvidos no processo de composição. Em relação à extensão dos nomes, percebe-se que a maior parte dos casos não ultrapassa mais que três elementos, ao contrário do que foi observado por Melatti (1976, p. 143), para o qual, às vezes, podem chegar a ser constituídos de sete ou mais palavras.

Na seção a seguir, analisamos, em uma perspectiva pragmática, o evento de transmissão de nomes pessoais como um ato de fala específico, cujo gênero do discurso apresenta certas propriedades específicas para essa finalidade.

\section{Teoria dos atos de fala}

A teoria dos Atos de Fala desenvolveuse na interrelação entre a Linguística e a Filosofia Analítica na primeira metade do século XX. Essa teoria tem como seu fundador e principal expoente o filósofo John

$\begin{array}{ll}\text { Catàmjê } & \\ \text { Capêr=kwỳj } & \text { bacaba=FEM } \\ \text { Pàn=kwỳj } & \text { arara=FEM } \\ \text { Amxy=kwỳj } & \text { maribondo=FEM } \\ \text { Jun=kwỳj } & \text { beija-flor=FEM } \\ \text { Tôn=kwỳj } & \text { tatu=FEM } \\ \text { Wakõ=kwỳj } & \text { quati=FEM }\end{array}$

Catàmjê

Langashaw Austin (1911-1960), que a formulou a partir de suas conferências na Universidade de Harvard, em 1955, reunidas postumamente na obra How to do Things with Words (AUSTIN, 1962) ${ }^{10}$.

A ideia central da teoria dos atos de fala de Austin (1981) é que o "emitir la expresión es realizar una acción y que ésta no se concibe normalmente como el mero decir algo"11 (p. 47) ou, nas palavras de Levinson (2010, p. 290), “o mundo mudou de maneiras substanciais”. Tomemos como ilustração os seguintes exemplos:

\section{(6) a. Hoje choveu pela manhã. b. Prometo que volto cedo.}

Observando enunciados desse tipo, Austin (1990) estabeleceu uma distinção clara entre ambos para criticar as condições de verdade, tidas como essenciais para a compreensão da linguagem pela Lógica Formal, corrente filosófica predominante na Europa na primeira metade do século XX. Desse modo, enunciados como 6(a) declaram so-

10. A edição tomada como referência neste estudo é a tradução espanhola: AUSTIN, John L. Como hacer cosas con palabras - Palabras y acciones. Compilado-por J. O. Urmson. Barcelona: Ediciones Paidos, 1990. 11. Tradução: "emitir a expressão é realizar uma ação e que esta não se concebe normalmente como o mero dizer algo" (AUSTIN 1990, p, 47) 
bre algo, enquanto enunciados, como 6(b), permitem realizar ações quando são proferidos, para os quais "a questão de verdade ou falsidade não surge” (LEVINSON,2010, p. 290). Austin (1990) denominou os primeiros de enunciados de constativos e os segundos de enunciados performativos, os quais: “A) no 'describen' o 'registran' nada, y no son 'verdaderas o falsas'; y B) el acto de expresar la oración es realizar una acción, o parte de ella, acción que a su vez no sería normalmente descripta como consistente en decir algo" (p. 45-46) ${ }^{12}$.

Austin (1962, apud LEVINSON, 2010) considerou que enunciados performativos podem dar errado, isto é, não executar a ação esperada. 0 autor toma como exemplo o batizado de um barco, nomeando-o. 0 mesmo não pode ser batizado caso já tenha recebido um nome ou a pessoa designada para essa finalidade não seja apropriada. Situações como essa "são necessários certos arranjos institucionais, sem os quais a ação que a enunciação tenta executar é simplesmente nula ou vazia” (LEVINSON, 2010, p. 291). A essas circunstâncias apropriadas, Austin (1962) chamou de condições de felicidade, para as quais distinguiu três categorias principais:

A. (i) Deve existir um procedimento convencional que tenha um efeito convencional; (ii) As circunstâncias e as pessoas devem ser adequadas, conforme especificado no procedimento;

B. 0 procedimento deve ser executado (i) corretamente e (ii) completamente;
C. Muitas vezes, (i) as pessoas devem ter os pensamentos, sentimentos e intenções requeridos conforme especificado no procedimento, e (ii) se a conduta consequente é especificada, então, as partes relevantes devem aterse a essa conduta (LEVINSON,2010, p. 291).

Partindo da premissa que, ao enunciarmos sentenças, estamos também fazendo coisas, Austin (1990) identifica três tipos básicos de sentidos por meio de três atos que são executados ao mesmo tempo: (i) ato locucionário, aqueles que dizem alguma coisa, isto é, "a enunciação de uma sentença com sentido e referência determinados" (LEVINSON, 2010, p. 300); (ii) ato ilocucionário, o ato de fazer uma declaração, oferta, promessa, etc., o qual reflete "a ação que se executa quando se fala” (ARMENGAUD, 2006, p. 100); ato perlocucionário são os efeitos produzidos nas pessoais às quais são dirigidas a enunciação.

Para os propósitos desse trabalho, não serão enfatizados os desdobramentos da teoria dos atos de fala inicialmente proposta por Austin (1962 [1990]). Propusemo-nos destacar os aspectos e os conceitos centrais de sua teoria que serão adotados na análise do discurso proferido durante o evento de transmissão de nome pessoal. A seção seguinte apresenta a transcrição e a tradução do discurso enunciado, que o caracterizam como um ato de fala específico, segundo suas propriedades linguísticas e função pragmática na cultura krahô.

12. Tradução: “A) não “descrevem” ou "registram” nada, e não são "verdadeiras ou falsas"; e B) o ato de expressar a oração é realizar uma ação, ou parte dela, ação que por sua vez não seria normalmente descrita como consistente em dizer algo" (Austin 1990, p. 45-46). 


\section{Transmissão de nome pessoal como um} ato de fala

0 discurso transcrito e traduzido que apresentamos, a seguir, está organizado como segue. Na primeira linha, indicamos o texto na escrita ortográfica krahô e, na li- nha seguinte, a transcrição fonética acompanhada da segmentação morfológica, de acordo com os intervalos da fala. Por fim, a tradução do enunciado para a qual buscamos manter as características principais da gramática krahô.

\title{
Parte I
}

\author{
inkrer $^{13}$ \\ in- $\mathrm{k}^{\mathrm{h}} \mathrm{r} \varepsilon-\mathrm{r}$ \\ REL-cantar-NOMLZ \\ canto
}
Hê ñe cumã (2x)
$\mathrm{He}=$ nẽ ku-mã
$\mathrm{ENF}=\mathrm{con} \quad$ REL-para
E é para ela (a garça)

$\begin{array}{llll}\text { wapri }^{14} & \text { wapri } & \text { tê } & \text { hê } \boldsymbol{n e} \mathbf{e}(\mathbf{2 x}) \\ \text { wapri } & \text { wapri } & \text { te } & \text { he=nẽ } \\ \text { garça } & \text { garça } & \text { aí } & \mathrm{ENF}=\mathrm{CON}\end{array}$

Aí é a garça, é a garça

\begin{tabular}{|c|c|c|c|c|c|}
\hline hĩpô & hĩpôc & jipôc & $\boldsymbol{c} \hat{\boldsymbol{o}}$ & ri & $x a=n \tilde{e}(2 x)$ \\
\hline hĩpo & hĩpôc & j-ipok & ko & $\varnothing$-ri & $\varnothing$-tsa $=$ nẽ \\
\hline lago & lago & REL-no.meio.de & água & REL-LOC & REL-estar.em.pé $=\mathrm{CON}$ \\
\hline
\end{tabular}

E, no meio do lago, ela está em pé na água

Parte II

\begin{tabular}{|c|c|c|c|}
\hline ha & $\begin{array}{l}x \tilde{a} m \quad p e a \\
\text { tsãm=pea }\end{array}$ & $\begin{array}{l}\boldsymbol{m} \tilde{\boldsymbol{e}} \quad \boldsymbol{i k r a} \\
\mathrm{m} \tilde{e}=\mathrm{i}=\varnothing-\mathrm{k}^{\mathrm{h}} \mathrm{ra}\end{array}$ & $\begin{array}{l}\boldsymbol{m} \tilde{\boldsymbol{e}} \quad \text { itàmxwỳj } \hat{\boldsymbol{e}} \\
\mathrm{me}=\mathrm{i}=\varnothing \text {-trmtswə-je } \\
\mathrm{PL}=1 \mathrm{SG}=\mathrm{REL}-\mathrm{filho}(\mathrm{a}) \text { da irmã } / \mathrm{ne}\end{array}$ \\
\hline RT & pronto & $\mathrm{PL}=1 \mathrm{SG}=\mathrm{R}^{1}$-filho & PL=1SG=REL-filho(a).da.irmã/ne \\
\hline
\end{tabular}

E pronto! Meus filhos, meus sobrinhos e netos

13. Abreviaturas: 1 - Primeira pessoa; 2 - Segunda pessoa; CLASS.POSS - Classificador possessivo; CON - Conectivo; DUAL - Dual; DUB - Dubitativo; ENF - Enfático; FOC - Foco; HORT - Hortativo; LOC - Posposição Locativa NOMLZ - Nominalizador; IRR - Irrealis; OBL - Oblíquo; PL - Plural; REL Prefixo Relacional que tem por função indicar que o determinante encontra-se contíguo ou não ao seu núcleo sintático, formando com ele uma unidade sintática; REFLX - Reflexivo; SG -Singular.

14. A palavra wapri corresponde à palavra capri (garça) na fala espontânea. Essa mudança da consoante inicial de $/ \mathrm{k} / \Rightarrow[\mathrm{w}]$ pode estar associada ao ritmo da fala na música. 
mẽ iwawỳ,

$\mathrm{me}=\mathrm{i}=\varnothing$-wawə

$\mathrm{PL}=1 \mathrm{SG}=\mathrm{REL}$-cunhado

Meus cunhados

$\begin{array}{llll}\boldsymbol{m} \tilde{\boldsymbol{e}} \boldsymbol{i} \boldsymbol{m} \tilde{\boldsymbol{a}} & \boldsymbol{c a} & \boldsymbol{m} \tilde{\boldsymbol{a}} & \boldsymbol{n} \tilde{\boldsymbol{a}} \\ \mathrm{m} \tilde{e}=\mathrm{i}=\varnothing \text {-mã } & \mathrm{ka} & \mathrm{mã} & \varnothing \text {-nã } \\ \mathrm{PL}=1 \mathrm{SG}=\mathrm{REL}-\mathrm{para} & 2 \mathrm{SG} & \mathrm{FOC} & \text { REL-sobre }\end{array}$

Para os meus (a comunidade) é você que avisas obre isso (a chegada).

\begin{tabular}{|c|c|c|c|}
\hline$-w a$ & pĩn & ijarẽn & cato $(2 x)$ \\
\hline -wa & jũ $=\varnothing$-pĩn & $\mathrm{i}=\mathrm{j}-\operatorname{arẽ}-\mathrm{n}$ & $\varnothing$ Ø-kato \\
\hline 1.SG & $\mathrm{INDEF}=\mathrm{R}^{1}-\mathrm{de}$ & $1 \mathrm{SG}=\mathrm{R}^{1}$-dizer-nomlz & REL-sair \\
\hline
\end{tabular}

- De algum lugar, eu saio dizendo (o dia que vai chegar a pessoa que recebe o nome)

$\begin{array}{lllll}\text { Ahprà } & \text { cuxwa, } & \text { akamter, } & \text { akra, } & \boldsymbol{a p r e}^{\mathbf{1 5},} \\ \varnothing \text {-a?pre } & \varnothing \text {-kutswa } & \mathrm{a}=\varnothing-\text {-kamter } & \mathrm{a}=\varnothing-\mathrm{k}^{\mathrm{h}} \mathrm{ra} & \mathrm{a}=\varnothing-\mathrm{pr} \varepsilon \\ \text { REL-chama } & \text { REL-gostoso } & \text { 2SG=REL-filho.rapaz } & \text { 2SG=REL-filho } & \text { 2SG=REL-irmão. } \\ & & & & \text { da.esposa }\end{array}$

$a w a w \grave{y}^{16}$

$\mathrm{a}=\varnothing$-wawə

2SG=REL-esposo.da.irmã

Chama (de fogo) gostosa, teu filho rapaz, teu filho, teu cunhado

$\begin{array}{llllll}\text { Ahprà } & \text { cuxwa } & \text { quê } & \text { ha } & \text { ita }=\text { kã } \boldsymbol{m} & \text { pôj } \\ \text { Ø-a?pre } & \varnothing \text {-kutswa } & \text { ke } & \text { ha } & \text { ita }=\mathrm{k}^{\mathrm{h}} \text { ãm } & \varnothing \text {-poj } \\ \text { REL-chama } & \text { REL-gostoso } & \text { FOC } & \text { IRR } & \text { hoje } & \text { REL-chegar }\end{array}$

Chama (de fogo) gostosa (Nomes pessoal), ele vai chegar hoje.
Ahprà cuxwa te mã ajpẽn pamã amjĩ jarẽn

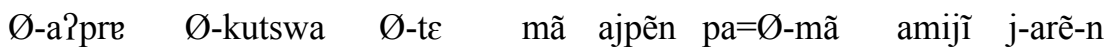
REL-chama REL-gostoso REL-OBL FOC DIR 1PL=RELpara REFLX REL-dizer-NOMLZ
Foi Chama (de fogo) gostosa que disse para nós mesmos

\begin{tabular}{|c|c|c|c|c|c|}
\hline Cu & pahtỳj & pahcunĩ & $p \hat{e}$ & $m \tilde{a}$ & hikaj \\
\hline $\mathrm{ku}$ & $\mathrm{pa} ?=\varnothing-\mathrm{t} \partial \mathrm{j}$ & pa?=Ø-kunĩ & $\varnothing$-pe & mã & h-ikaj \\
\hline 1PL/DUAL & 1PL=REL-dever/poder & 1PL=REL-todos & REL-LOC & FOC & REL-esperar \\
\hline
\end{tabular}

15. Termo usado para referir-se indiretamente ao irmão da esposa de ego masculino.

16. Usa-se este termo para designar a forma recíproca com a qual o irmão da esposa dirige-se indiretamente ao esposo dela. 


\begin{tabular}{|c|c|c|c|c|c|c|}
\hline Ahprà & cuxwa & $q u \hat{e}$ & $h a$ & pôj & pahwỳr & mãrhã \\
\hline$\varnothing$ Ø-åpre & Ø-kutswa & ke & ha & Ø-рој & pa?=Ø-wər & mãrhã \\
\hline REL-chama & REL-gostoso & ENF & IRR & REL-chegar & 1PL=REL-em.direção.de & DUB \\
\hline
\end{tabular}

$\begin{array}{ll}\boldsymbol{j} \tilde{\boldsymbol{u}} \quad \boldsymbol{r i} & \boldsymbol{h} \tilde{\boldsymbol{o}} \quad \boldsymbol{k} \boldsymbol{\boldsymbol { i }} \\ \text { jũ }=\varnothing-\mathrm{ri} & \mathrm{h}-\tilde{\mathrm{o}}=\mathrm{k}^{\mathrm{h}} \mathrm{rĩ} \\ \text { INDEF=REL-de } & \text { REL-CLASS.POSS=aldeia }\end{array}$

Chama gostosa vai chegar no rumo de nós talvez de algum lugar, da aldeia dele.

\begin{tabular}{|c|c|c|c|c|}
\hline Quê & $h a$ & pamã & $h \tilde{\boldsymbol{o}} \quad k r \tilde{i}$ & jarẽ \\
\hline ke & ha & $\mathrm{pa}=\varnothing-\mathrm{mã}$ & $\mathrm{h}-\tilde{\mathrm{o}}=\mathrm{k}^{\mathrm{h}} \mathrm{r} \tilde{\mathrm{I}}$ & $\mathrm{j}$-arẽ \\
\hline ENF & IRR & 1PL=REL-para & REL-CLASS.POSS=aldeia & REL-dizer \\
\hline
\end{tabular}

É ele (A?pŕa cuxwa) que vai dizer a aldeia dele para nós

\begin{tabular}{|c|c|c|c|}
\hline 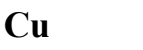 & ha & krĩ & jahkrepej \\
\hline 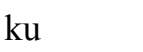 & ha & $\mathrm{h}-\tilde{\mathrm{O}}=\mathrm{k}^{\mathrm{h}} \mathrm{r} \tilde{1}$ & $\mathrm{j}-\mathrm{a} 2 \mathrm{k}^{\mathrm{h}} \mathrm{rep} \boldsymbol{\mathrm { j }}$ \\
\hline UAL & IRR & POSS $=$ aldeia & REL-saber \\
\hline
\end{tabular}

Nós vamos saber da aldeia dele

\begin{tabular}{|c|c|c|c|c|c|c|c|c|}
\hline & $n \tilde{a}$ & cu & $h a$ & $r a$ & $a m j \tilde{\imath}$ & $w y \grave{r}$ & mẽ hahkrepej & pej \\
\hline & $\mathrm{m}$ & $\mathrm{ku}$ & ha & $\mathrm{ra}$ & amjĩ & $\varnothing$-wər & $m \tilde{e}=\mathrm{h}-\mathrm{a} P \mathrm{k}^{\mathrm{h}} \mathrm{r} \varepsilon p \varepsilon j-\varnothing$ & E] \\
\hline & FOC & 1PL/DUAL & IRR & já & REFLX & REL-em.direção.de & $\mathrm{PL}=$ REL-saber-NOMLZ & \\
\hline
\end{tabular}

Nós já vamos saber bem dele na direção de nós mesmos (quando ele vier em nossa direção)

$\begin{array}{lllllll}\text { mã } & \mathbf{c u} & \text { ha } & \text { ramã } & \text { amẽ } & \text { papa } & \text { kãm } \\ \text { mã } & \mathrm{ku} & \text { ha } & \text { ramã } & \text { amẽ } & \text { pa=Ø-pa } & \varnothing-k^{\mathrm{h} a ̃ m} \\ \text { FOC } & 1 \mathrm{PL} / \mathrm{DUAL} & \mathrm{IRR} & \text { já } & \mathrm{COL} & 1 \mathrm{PL}=\text { REL-ficar } & \text { REL-LOC }\end{array}$

Nós que já vamos ficar juntos (em algum lugar)

$\begin{array}{lll}\text { ramã } & \text { ate } & \text { mẽ } \quad \text { ipar } \\ \text { ramã } & a=\varnothing-t \varepsilon & m \tilde{=}=\mathrm{i}=\varnothing-\text { pa-r } \\ \text { já } & 2 \mathrm{SG}=\mathrm{REL}-\mathrm{OBL} & \mathrm{PL}=1 \mathrm{SG}=\mathrm{REL}-\text { escutar-NOMLZ } \\ \text { E vocês já me escutaram } & \end{array}$

17. A prática de carregar as pessoas que receberão nomes evidencia um sistema de troca de presentes, ou seja, a pessoa carregada passa a ter uma "dívida" que deverá ser paga com presentes a fim de recompensar o esforço de ter sido carregado, uma vez que nem todas as pessoas dispõem-se a tal tarefa. 
Para fins de análise, dividimos o discurso proferido de transmissão de nome pessoal em duas partes: a primeira caracteriza-se por ser cantada e serve como um exórdio ao discurso que é entoado em seguida, marcado por uma cadência melódica distinta da fala espontânea, enquanto a segunda constitui o discurso propriamente dito. Para os propósitos deste artigo, destacaremos algumas partes que caracterizam tal discurso como um ato de fala específico.

0 rito de nominação de não indígenas inicia-se logo cedo, quando a pessoa que receberá o nome é carregada nas costas pelas pessoas que se revezam e é levada ao córrego mais próximo para o banho. 0 nominado é carregado por pessoas do sexo oposto, ou seja, os homens são carregados pelas mulheres e as mulheres pelos homens ${ }^{17}$. Solicita-se que a pessoa mergulhe na água e, em seguida, o executor do rito profere algumas palavras. Após esse momento, carregase novamente nas costas a pessoa em direção ao pátio da aldeia cà, no qual é cortado o cabelo, de acordo com o modo tradicional krahô por uma das parentes. Em seguida, o corpo é pintado com urucum, conforme a orientação da pintura da metade (horizontal = catàmjê; vertical = wacmẽjê) e são gru- dadas penas no corpo com pau de leite. Depois dessas etapas, formam-se duas fileiras no pátio da aldeia no sentido norte-sul. A pessoa que recebe o nome é tomada na mão esquerda pelo seu nominador e na mão direita pelo executor do rito, os quais passam entre as filas de duas a três vezes. Terminado esse momento, o executor do rito profere as seguintes palavras: Agora você vai chamar este(a) de teu/tua quêtti/tỳj e ele(a) vai te chamar de ipantu. 0 enunciado proferido identifica-o como um ato ilocucionário, a partir do qual o ato de fala de transmissão do nome pessoal é realizado.

Diferente de outras línguas que possuem verbos específicos para tal ato, como em português "batizar" ou "nomear", e executado por pessoas específicas, na sociedade krahô, além do mestre do rito, essa ação é transferida e desempenhada pelos indivíduos envolvidos no evento, isto é, quêti/tyj-ipantu, numa relação de reciprocidade em que ambos passam a se chamar/tratar por esses termos. Esse ato de fala demonstra que "o mundo mudou de maneiras substanciais" (LEVINSON, 2010, p. 290). Para finalizar o rito, a pessoa nominada recebe vários presentes da comunidade à qual passa a partir de então a pertencer.

18. A relação de reciprocidade, que marca o vínculo entre nominadores e nominados, não é expressa no ato ilocucionário de nominação de indivíduos Krahô. Isso se explica pelo fato de as crianças recém-nascidas serem nominadas após seu nascimento, ao contrário de outros povos Jê, como, por exemplo, entre os Xavante, em que a criança não pode receber um nome logo que nasce, pois "o nome é uma carga pesada demais para o seu corpo frágil, ‘mole', que acabará adoecendo até morrer” (SILVA 1986, p. 65). 


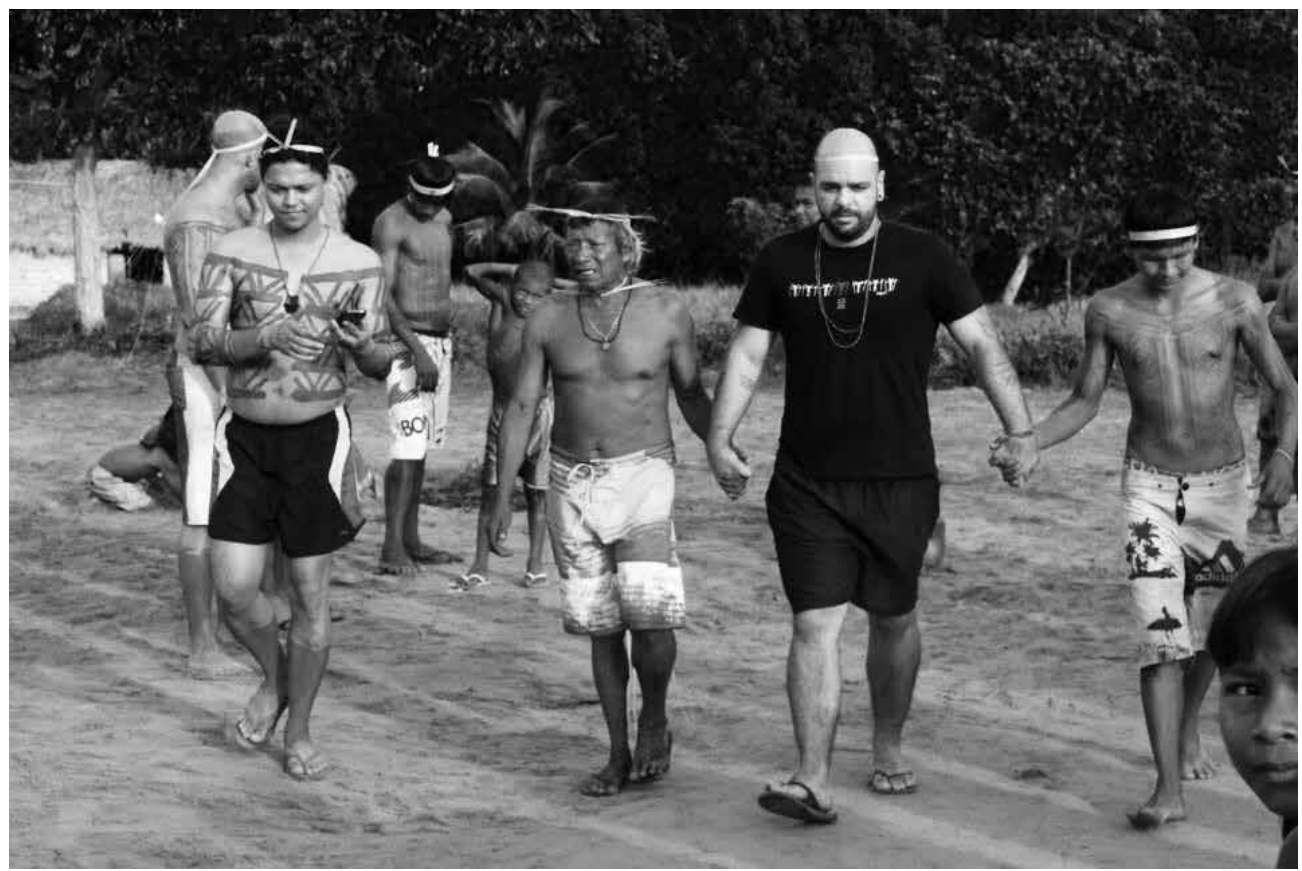

Fonte: Foto de Roberto Dalmo, 2015.

É importante destacar a relação temporal marcada pelo advérbio agora, cuja ocorrência sinaliza um divisor entre o antes e o depois do ato. Como podemos notar, ao contrastar a transmissão de nome a não indígenas com a de indivíduos nascidos no grupo, o ato ilocucionário difere quanto aos procedimentos convencionalizados, mas apresenta as mesmas características linguísticas, conforme menciona Melatti (1978, p. 115):

0 nome é dado dentro de casa, depois que o recém-nascido toma seu primeiro banho. Diz o transmissor do nome: Agora esse (essa) ai é meu (minha) ipantu' (grifos nossos). 0 transmissor deve ir à casa da criança logo depois do nascimento, para doar seu nome. Se mora em outra aldeia, deve recomen- dar que seu nome seja atribuído à criança, ao nascer, se for de seu sexo. Se o nome dado for Wakmejê, um líder da metade dá seu grito característico, na praça, de manhã, depois do sol nascer; se o nome for Katamye, um dos líderes desta metade faz o mesmo, mas antes do sol sair.

Embora a pessoa nominada passe a pertencer à complexa rede de parentesco, o discurso proferido na nominação de não indígenas também é marcado pela relação espacial, cujo contraste se dá entre os que vivem no espaço da(s) aldeia(s) e aqueles que não vivem, mas se acham ligados a ela(s) a partir da nominação, conforme se verifica no seguinte trecho. 


$\begin{array}{llll}\text {-wa } & \text { jĩ pĩn } & \text { ijarẽn } & \text { cato (2x) } \\ \text { — wa } & \text { jũ=Ø-pĩn } & \mathrm{i}=\mathrm{j} \text {-arẽ-n } & \text { Ø-kato } \\ \text { 1SG } & \text { INDEF=REL-de } & \text { 1SG=REL-dizer-NOMLZ } & \text { REL-sair }\end{array}$

— De algum lugar, eu saio dizendo (o dia que vai chegar a pessoa que recebe o nome)

$\begin{array}{lllll}\text { Ahprà } & \text { cuxwa, } & \text { akamter, } & \text { akra, } & \text { apre, } \\ \varnothing \text {-a?pre } & \varnothing \text {-kutswa } & \text { a=Ø-kamter } & \mathrm{a}=\varnothing-\mathrm{k}^{\mathrm{h}} \mathrm{ra} & \mathrm{a}=\varnothing \text {-pre } \\ \text { REL-chama } & \text { REL-gostoso } & \text { 2SG=REL-filho.rapaz } & \text { 2SG=REL-filho } & \text { 2SG=REL-irmão.da.esposa }\end{array}$

awawy

$\mathrm{a}=\varnothing$-wawə

2SG=REL-esposo.da.irmã

Chama (de fogo) gostosa, teu filho rapaz, teu filho, teu cunhado

$\begin{array}{llllll}\text { Ahprà } & \text { cuxwa } & \text { quê } & \text { ha } & \text { ita } \text { kãm } & \text { pôj } \\ \text { Ø-a?pre } & \varnothing \text {-kutswa } & \text { ke } & \text { ha } & \text { ita }=\mathrm{k}^{\mathrm{h}} \text { ãm } & \varnothing \text {-poj } \\ \text { REL-chama } & \text { REL-gostoso } & \text { ENF } & \text { IRR } & \text { hoje } & \text { REL-chegar } \\ \text { É Chama (de fogo) gostosa (Nomes pessoal) que vai chegar hoje. }\end{array}$

Além de marcar a ausência da pessoa nominada, no espaço da aldeia, já que esta é não indígena, o discurso ainda revela a preocupação dos Krahô em manter as relações estabelecidas com seus "novos" mem- bros, uma característica bastante peculiar do povo, demonstrada pela necessidade de saber o lugar de origem do nominado, a fim de obter informações quando este passa algum tempo sem visitar seus parentes mẽhĩ.

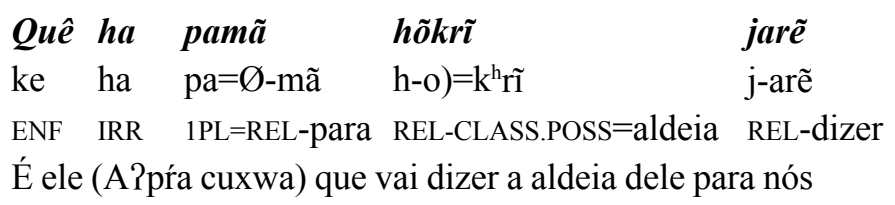

$\begin{array}{llll}\boldsymbol{C u} & \boldsymbol{h a} & \boldsymbol{h} \tilde{\boldsymbol{o}} \boldsymbol{k} \tilde{\boldsymbol{i}} & \text { jahkrepej } \\ \mathrm{ku} & \mathrm{ha} & \mathrm{h}-\overline{\mathrm{o}}=\mathrm{k}^{\mathrm{h}} \mathrm{ri} & \mathrm{j}-\mathrm{a} \mathrm{k}^{\mathrm{h}} \mathrm{r} \varepsilon \mathrm{p} \varepsilon \mathrm{j} \\ \text { 1PL/DUAL } & \text { IRR } & \text { REL-CLASS.POSS=aldeia } & \text { REL-saber }\end{array}$

Nós vamos saber da aldeia dele

0 discurso da nominação de não indígenas cumpre pragmaticamente seu papel no rito em questão, ao combinar elementos linguísticos com procedimentos convencionais executados durante a sua realização, ainda que difıra em certos aspectos do rito em que são transmitidos os nomes pes- soais aos indivíduos indígenas nascidos no grupo. Nesse aspecto, algumas questões devem ser consideradas quanto à (i) existência de possíveis variações no discurso de nominação entre as aldeias ou outros povos Timbira, ainda que o modo como é executado seja em princípio o mesmo, e (ii) às diferen- 
ças com respeito às etapas e à organização interna do discurso proferido na nominação daqueles que nascem no interior do grupo, em oposição aos não indígenas ou indígenas de outras aldeias.

\section{Considerações finais}

Exploramos, neste artigo, o rito de transmissão dos nomes pessoais, destacando a nominação de não indígenas a partir da análise do discurso proferido durante o rito na perspectiva da Teoria dos atos de fala (AUSTIN, 1990). Em um primeiro momento, discorremos sobre o campo de estudo da onomástica e, em seguida, ressaltamos o papel que a nominação dos indivíduos desempenha nas sociedades Jê, embora apresente diferenças quanto às regras de transmissão e às funções que exercem na vida política e sociocultural desses povos. Nesse sentido, mostramos como a transmissão dos nomes pessoais está intimamente relacionada com a organização da sociedade krahô, a qual é dividida em duas metades principais - catàmjê e wacmẽjê. A cada metade é associada uma série de nomes pessoais, como observou Melatti (1973, 1976, 1978). Ilustramos a filiação dos nomes a cada umas dessas metades e como alguns deles encarnam "personagens" em determinados momentos da vida social e ritual, conforme observou Melatti (1976).

Ao lado desses aspectos socioculturais da onomástica (antroponímia) krahô, descrevemos e analisamos os mecanismos linguístico-gramaticais envolvidos no processo de composição dos nomes pessoais, as classes de palavras que podem se combinar e as relações semânticas estabelecidas nesse processo. Conceber o rito de nominação krahô como um ato de fala implica compreendê-lo de que modo, a partir desse evento, ocorre a instauração de uma complexa rede de relações recíprocas e de evitação, que são operadas e reguladas no domínio dos nomes pessoais, dos quais o indivíduo seja portador - como são as relações entre parentes próximos e a amizade formal.

A onomástica krahô, por meio de seus antropônimos, constitui-se uma das principais vias para compreendermos os princípios sociais e culturais que regem a organização dessa sociedade e os modos de agir de seus membros entre si e em distintos eventos de fala. 0 enfoque pragmático possibilitou-nos compreender várias nuances envolvidas na transmissão de nomes pessoais, revelando padrões e práticas sociais institucionalizadas na sociedade krahô. Este estudo, portanto, representa uma contribuição aos estudos sobre essa sociedade que, apesar de estar em contato com a sociedade não indígena desde a primeira metade do século XIX, ainda mantém e realiza boa parte de seus ritos, como estratégia de resistir às pressões externas que vêm sofrendo nos últimos anos.

\section{Referências}

ALGE0, J. ALGE0, K. Onomastics as an interdisciplinary study. Names, n. 48, p. 265-274, 2000.

AUSTIN, J. L. Como hacer cosas con palabras Palabras y acciones. $3^{\text {a }}$ reimpresión. Barcelona: Ediciones Paidos, 1990.

ARMENGAUD, F. A pragmática. São Paulo: Parábola Editorial, 2006.

CROCKER, W. H. Os Canelas: parentesco, ritual e sexo em uma tribo da chapada maranhense. Rio de Janeiro: Museu do Índio, 2009.

BRIGHT, W. What is a name? Reflections on Onomastics. Language and Linguistics, n. 44, p. 669681, 2003.

LADEIRA, M. E. A troca de nomes e a troca de cônjuges - uma contribuição ao estudo do parentesco Timbira. Dissertação (Mestrado em Ciências Sociais) - FFCLH, Universidade de São Paulo, São Paulo, 1982. 
LEA, V. R. Riquezas intangiveis de pessoas partiveis: os Mẽbêngôkre (Kayapó) do Brasil Central. São Paulo: Edusp e Fapesp, 2012.

. Mebengokre (Kayapo) Onomastics: a faceta of house as total social facts in Central Brazil. Man, New Series, v. 27, n. 1, p. 129-153, 1992.

. Nomes e nekrets Kayapó: uma concepção de riqueza. (Tese de Doutorado). Rio de Janeiro. PPGAS- Museu Nacional/UFRJ, 1986.

LÉVI-STRAUSS, C. As estruturas elementares do parentesco. Petrópolis: Vozes, 1982.

LEVINSON, S. C. Pragmática. São Paulo: Martins Fontes, 2010.

MAYBURY-LEWIS, D. Dialectical Societies - The Ge and Bororo of Central Brazil. Cambridge: Harvard University Press, 1979.

MELATTI, J. C. Ritos de uma tribo Timbira. São Paulo: Ática, 1978.

. 0 sistema de parentesco dos índios Krahó. Série Antropologia n. 3. Departamento de Antropologia, Instituto de Ciências Sociais da Universidade de Brasília. Brasília: UnB, 1973.

. Nominadores e genitores: um aspecto do dualismo craô. In: SCHADEN, E. (Org.). Leituras de etnologia brasileira. São Paulo: Companhia Editora Nacional, 1976, p. 139-148.

MIRANDA, M. G. Morfologia e morfossintaxe da língua Krahô (família Jê, tronco Macro-Jê). 2014. 323f. Tese (Doutorado em Linguística) - PPGL, Universidade de Brasília, Brasília, 2014.

As nominalizações na sintaxe da

língua Krahô (Jê). 2010. 96f. Dissertação (Mestrado em Linguística) - PPGL, Universidade de Brasília, Brasília, 2010.

NIMUENDAJÚ, C. The eastern Timbira. Berkeley \& Los Angeles: University of California Publications in American Archeology and Ethnology, 1946.

SILVA, A. L. Nomes e amigos: da prática Xavante a uma reflexão sobre os Jê. São Paulo: FFLCH/ USP, Série Antropologia n. 6, 1986.

UTLEY, F. L. The linguistic component of onomastics. Names, n. 11, p. 145-176, 1963.

VEIGA, J. Aspectos fundamentais da cultura Kaingang. Campinas, SP. Editora Curt Nimuendajú, 2006. 
RESUMO

Este artigo analisa, do ponto de vista semântico-pragmático, os nomes pessoais krahô, e os modos como eles refletem alguns traços da organização social do povo como um todo. É mostrada a distribuição dos nomes masculinos e femininos nas metades principais, wacmẽjê e catàmjê, e sua relação com determinados papéis sociais desempenhados em alguns ritos. Destacase também que o rito de nominação, como um ato de fala, é caracterizado na sociedade krahô não apenas como a particularização de um indivíduo dentro do grupo, mas envolve na mesma medida a transmissão de certas prerrogativas sociais que acompanham o nome pessoal, semelhante ao que é observado em outras sociedades Jê.

\section{PALAVRAS-CHAVE}

Onomástica. Antroponímia. Nominação. Rito. Krahô.

\section{ABSTRACT}

This paper analyzes, from the semantic -pragmatic point of view, the personal names krahô, and the ways in which they reflect some traces of the social organization of the people as a whole. It shows the distribution of male and female names in the main halves, wacmẽjê and catàmjê, and their relation to certain social roles played in some rites. It is also noted that the rite of nomination, as an act of speech, is characterized in krahô society not only as the particularization of an individual within the group, but also involves the transmission of certain social prerogatives that accompany the personal name, similar to which is observed in other Jê societies.

\section{KEYWORDS}

Onomastics. Antroponymy. Nomination. Rite. Krahô. 